\title{
THIN RESISTIVE THICK-FILM LAYERS BASED ON PRECIOUS METAL RESINATE/GLASS SYSTEMS
}

\author{
P. PRINSEN \\ N. V. Philips, Eindhoven, Netherlands
}

(Received August 16, 1977)

\begin{abstract}
This paper describes the preparation and results obtained with a ruthenium-resinate/glass resistive system prepared by firing on to a $96 \%$ alumina substrate. The results have been compared with a gold/rhodium-resinate/glass system. It is found in the ruthenium system that the particle size is about $200 \AA$ and because of this, conduction occurs at a very low volume percent conduction phase. Temperature Coefficient of Resistance behaviour of the ruthenium based system is still anomalous.
\end{abstract}

\section{INTRODUCTION}

Liquid precious metals (resinates) were already used before 1900 to decorate glass and enamel. Voigt and Haeffner ${ }^{1}$ patented these decorative materials in 1899 for making thin resistive layers on enamel.

A combination of liquid precious and base metals was used by Cockbain, ${ }^{2}$ to produce $2 \mu$-thick resistive layers on ceramic substrates. In this system the base metal-resinates provide the glass phase.

The majority of present-day resistive screen pastes are composed of metal (oxide) and glass particles, dispersed in a rheological system of resins and solvents. The thickness of the fired resistive layers is about $10-20 \mu$.

The aim of this investigation is to compare resistivity, particle size and temperature coefficient of relatively simple precious metal resinate/glass systems with each other and with metal powder/glass systems.

\section{PRECIOUS METALRESINATES FROM NATURAL RAW MATERIALS}

Chemnitius $^{3}$ and Boudnikoff ${ }^{4}$ describe the reaction of sulfurised natural resins with precious metal salts, giving black tar-like resinates, which could be dissolved in a number of essential oils. The chemical structure of a natural resinate solution can only be roughly characterised by a number of analytical methods.

The decomposition process during firing can be followed by thermo-gravimetrical analysis, which is shown in Figure 1.

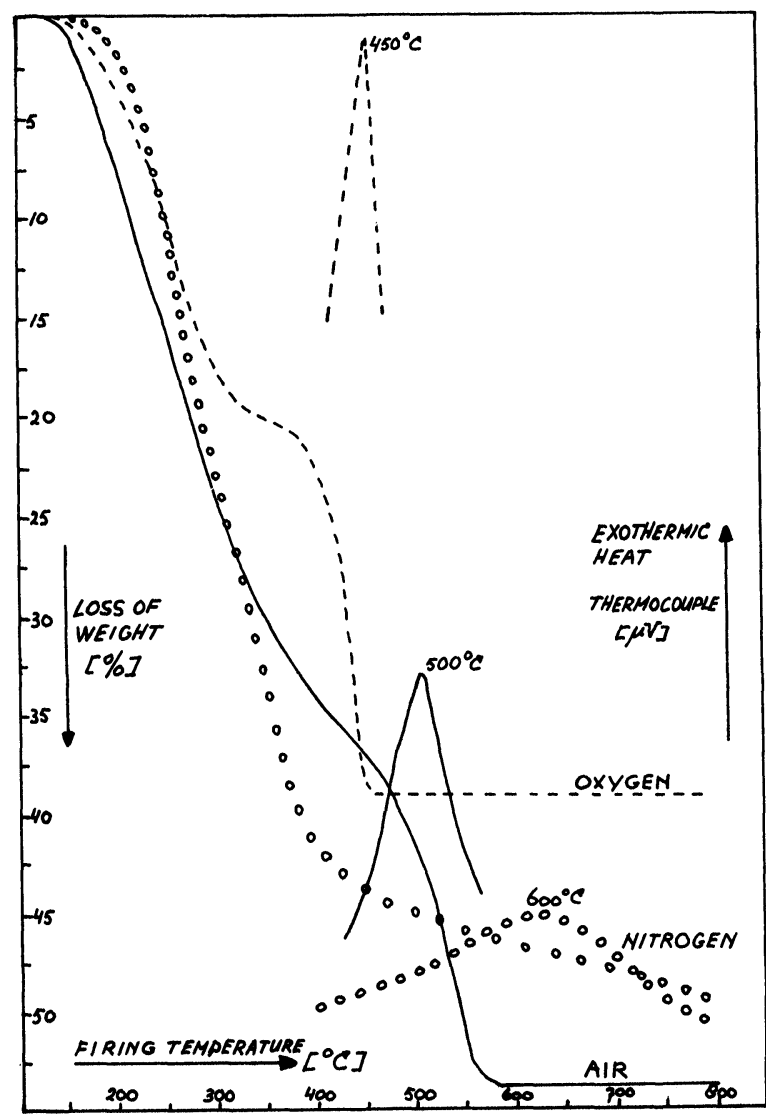

FIGURE 1 Decomposition of a mixture of several natural precious metal resinates. 
Because of the present-day interest in $\mathrm{RuO}_{2}$-based resistive layers, we decided to compare a gold- rhodium-resinate/glass system, investigated by Biesterbos, ${ }^{5}$ with a ruthenium-resinate/glass system.

\section{EXPERIMENTAL}

A glass powder with a specific surface area of $3 \mathrm{~m}^{2} /$ gram, was obtained by ballmilling a conventional lead-boro-alumino-silicate frit. The frit was characterised by a density of $4.5 \mathrm{~g} / \mathrm{cm}^{3}$, a softening point of $400^{\circ} \mathrm{C}$ and a thermal expansion coefficient of $73.10^{-7}$ in the region $30-300^{\circ} \mathrm{C}$.

Pastes were made by thoroughly dispersing the glass particles in concentrated resinate solutions. The amount of resinate and glass were chosen so that the volume fraction of conductor $\left(\mathrm{Au}-\mathrm{Rh}\right.$ or $\left.\mathrm{RuO}_{2}\right)$ in the fired film was between 1.5 and 10.0 vol.\%. Rhresinate is necessary to inhibit diffusion of fine gold particles. The resinate/glass pastes were applied to

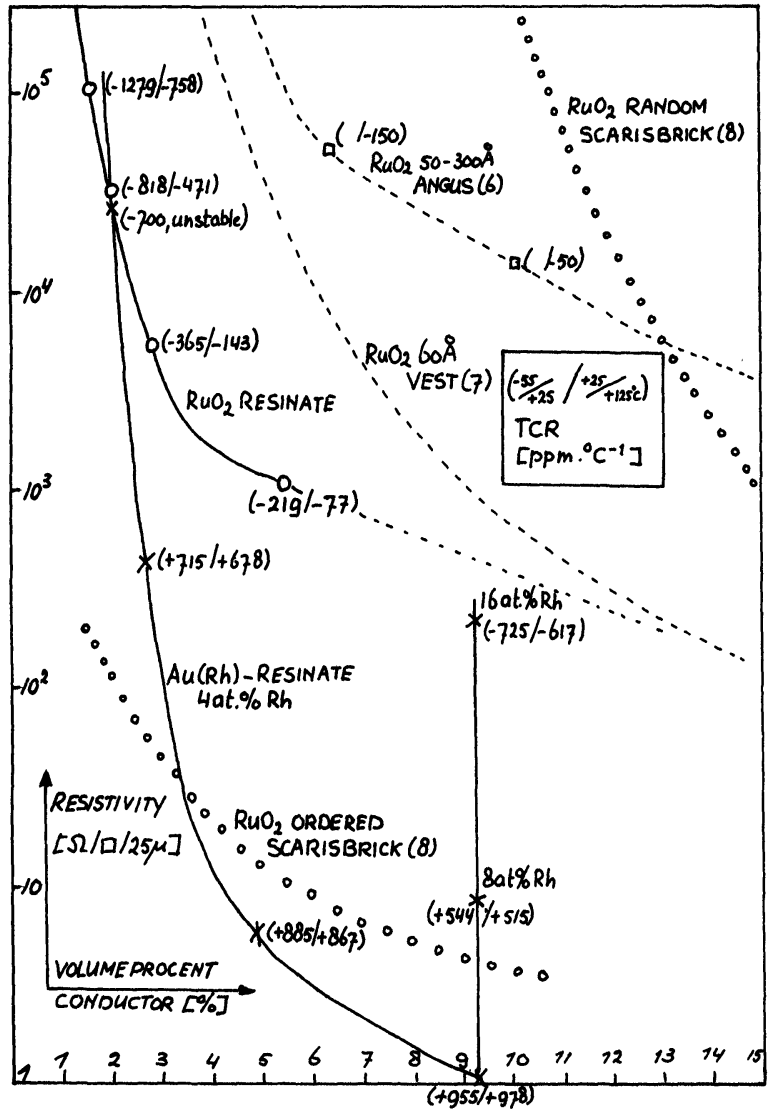

FIGURE 2 Resistivity of $\mathrm{Au} / \mathrm{Rh}$ glass and $\mathrm{RuO}_{2} /$ glass systems.
$96 \%$ alumina substrates by screen printing through a 325 mesh screen.

After 10 minutes firing in air at $725^{\circ} \mathrm{C}$, resistive layers were obtained with a thickness between 3.1 and 4.6 micron.

\section{RESULTS}

In Figure 2 we have plotted the resistivities $(\Omega / \square / 25 \mu)$ versus the vol.\% $\mathrm{Au}(\mathrm{Rh})$ and $\mathrm{RuO}_{2}$. In order to get a first impression of TCR-behaviour, we measured the resistances of each specific layer at $-55^{\circ} \mathrm{C},+25^{\circ} \mathrm{C}$ and $+125^{\circ} \mathrm{C}$. The TCR's for the regions $-55 /+25^{\circ} \mathrm{C}$ and $+25 /+125^{\circ} \mathrm{C}$ are marked on Figure 2 between brackets. The dashed lines (Figure 2) represent experimental data of Angus ${ }^{6}$ and Vest ${ }^{7}$ for various resistivities of $\mathrm{RuO}_{2}$ crystallites $(50-300 \AA)$ in lead-boroalumino-silicate glass.

The dotted lines (Figure 2) are calculated resistivities of $\mathrm{RuO}_{2}$ in glass, according to the theory of Scarisbrick, ${ }^{8}$ for random- and ordered (concentrated) dispersion of touching $\mathrm{RuO}_{2}$ particles in glass.

\section{DISCUSSION}

\subsection{The Au/Rh Glass System}

This system, with $\mathrm{Au} / \mathrm{Rh}$ particles, made from organometallic precursors (resinates), was investigated by Milgram ${ }^{9}$ and Biesterbos, ${ }^{5}$ who supposed that small $\mathrm{Rh}_{2} \mathrm{O}_{3}$ barriers inhibit the diffusion of $200 \AA$ gold particles.

The percolation threshold in Figure 2 (2.0 vol.\%) is quite different from predicted ${ }^{10}$ and measured ${ }^{11}$ values $(30 \mathrm{vol} . \%)$ for systems with gold and glass particles of similar size.

Using $2.0 \mathrm{vol} . \%$ conductive particles of $200 \AA$, it is possible to cover $47 \%$ of the glass surface, which indicates that some conduction should be possible.

$\mathrm{Au} / \mathrm{Rh} / \mathrm{glass}$ films with 4 at. \% Rh have positive TCR's. However in the region of 2.0 vol.\% Au, the layers are unstable (probably discontinuous) with negative TCR's.

For $\mathrm{Rh} \geqslant 13$ at. \%, Biesterbos ${ }^{5}$ made some films of about $50 \Omega / \square / 25 \mu$, with TCR's $<|10| \mathrm{ppm} .{ }^{\circ} \mathrm{C}^{-1}$, in the region $-190 /+130^{\circ} \mathrm{C}$.

In these films, the gold particles are supposed to be covered completely with a $10 \AA \mathrm{Rh}_{2} \mathrm{O}_{3}$ barrier, which governs the electrical conduction by a tunneling process. 


\subsection{The $\mathrm{RuO}_{2} /$ Glass System}

A 50\% coverage of the glass at a percolation threshold (Figure 2) of $1.0 \mathrm{vol} . \%$, is realised by $90 \AA \mathrm{RuO}_{2}$ crystallites. Our resistivities for vol.\% $\mathrm{RuO}_{2} \leqslant 5 \%$, are 20-300 times lower than values realised by Vest ${ }^{7}$ with $60 \AA \mathrm{RuO}_{2}$ crystallites. For this reason, our crystallites should be smaller than $60 \AA$. There are, however, indications that the particle size is about $200 \AA$, which means that we are probably dealing with a different coverage of the glass surface, according to Scarisbrick. ${ }^{8}$

$\mathrm{RuO}_{2}$ films with 10 vol.\% conductive phase show a much higher resistivity and lower TCR than corresponding $\mathrm{Au} / \mathrm{Rh}$ glass films, with respect to resistivities and TCR's of bulk materials. Either the $\mathrm{RuO}_{2}$ particles have different properties to the bulk material, or contact between two particles is different from the situation in the gold/glass system.

The presence of an unknown barrier between two $\mathrm{RuO}_{2}$ particles is also possible. This barrier differs from the $\mathrm{Rh}_{2} \mathrm{O}_{3}$ type, since TCR's in the $\mathrm{RuO}_{2}$-glass system are strongly dependent on the temperature.

\section{CONCLUSIONS}

It is possible to create interesting resistive metal/glass films of about 3.5 micron thick, with $\mathrm{Au} / \mathrm{Rh}$ and $\mathrm{Ru}$ resinate, together with lead-boro-alumino-silicate glasspowder. Thanks to the large number of $200 \AA$ conductor particles, conduction occurs at a low vol.\% conductive phase. The TCR-behaviour of the $\mathrm{RuO}_{2}$ /glass system is anomalous.

\section{REFERENCES}

1. J. Voigt and J. Haeffner, United States Patent 617.375 (1899).

2. A. Cockbain, British Patent 1.166 .992 (1966).

3. Chemnitius, J. Prakt. Chem., 117, 245 (1927).

4. Boudnikoff, Comp. Rend., 196, 1898 (1933).

5. J. Biesterbos, J. Appl. Phys., 45, 153 (1974).

6. H. Angus, et. al., United States Patent 3.679.607 (1972).

7. R. Vest, 8th Int. Symp. React. Solids, Gothenburg (1976).

8. R. Scarisbrick, J. Phys. D:Appl. Phys., 6, 2098 (1973).

9. A. Milgram, J. Electrochem. Soc., 118, 287 (1971).

10. S. Kirkpatrick, Rev. Modern Phys., 45, 574 (1973).

11. German Patent 1816105. 

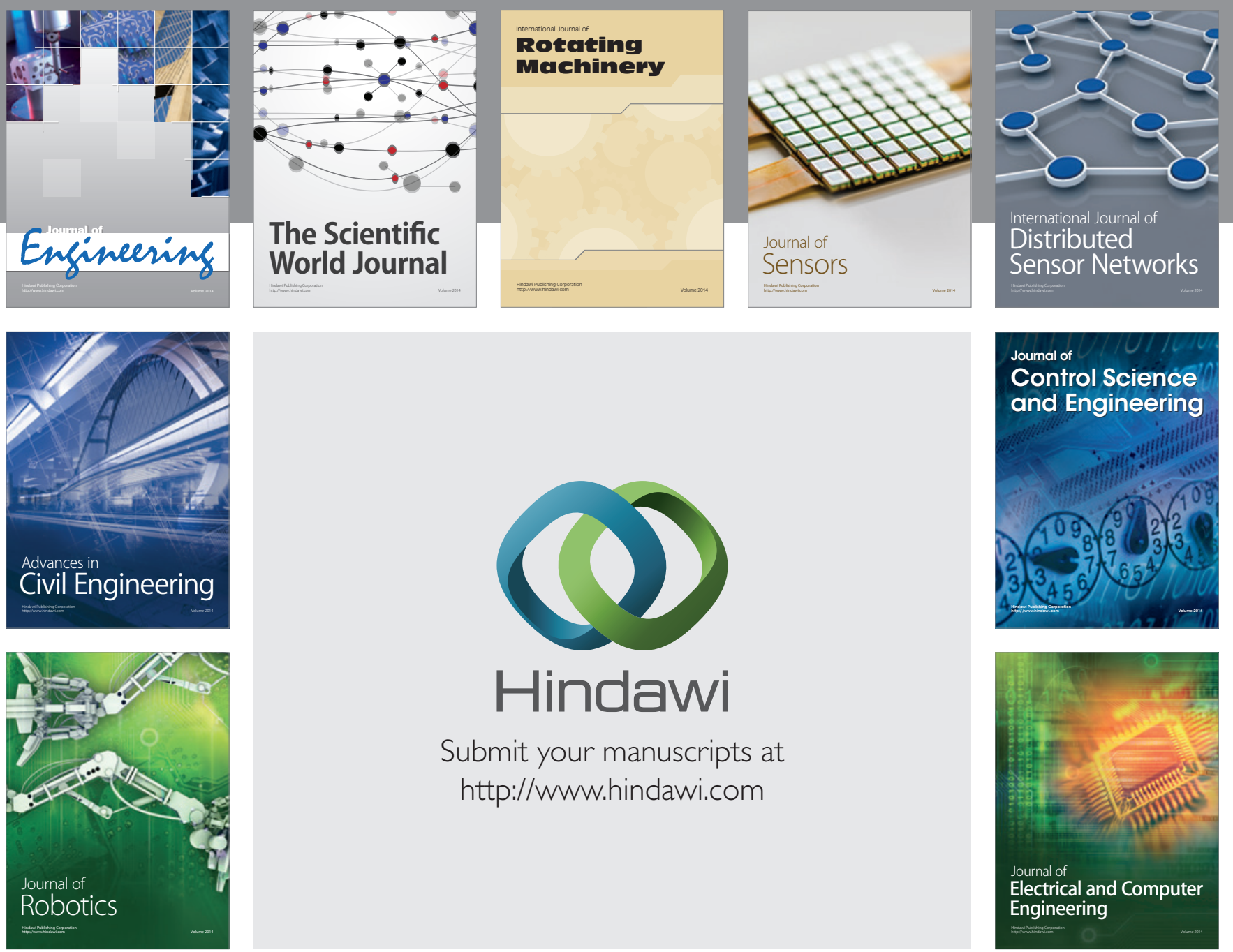

Submit your manuscripts at

http://www.hindawi.com
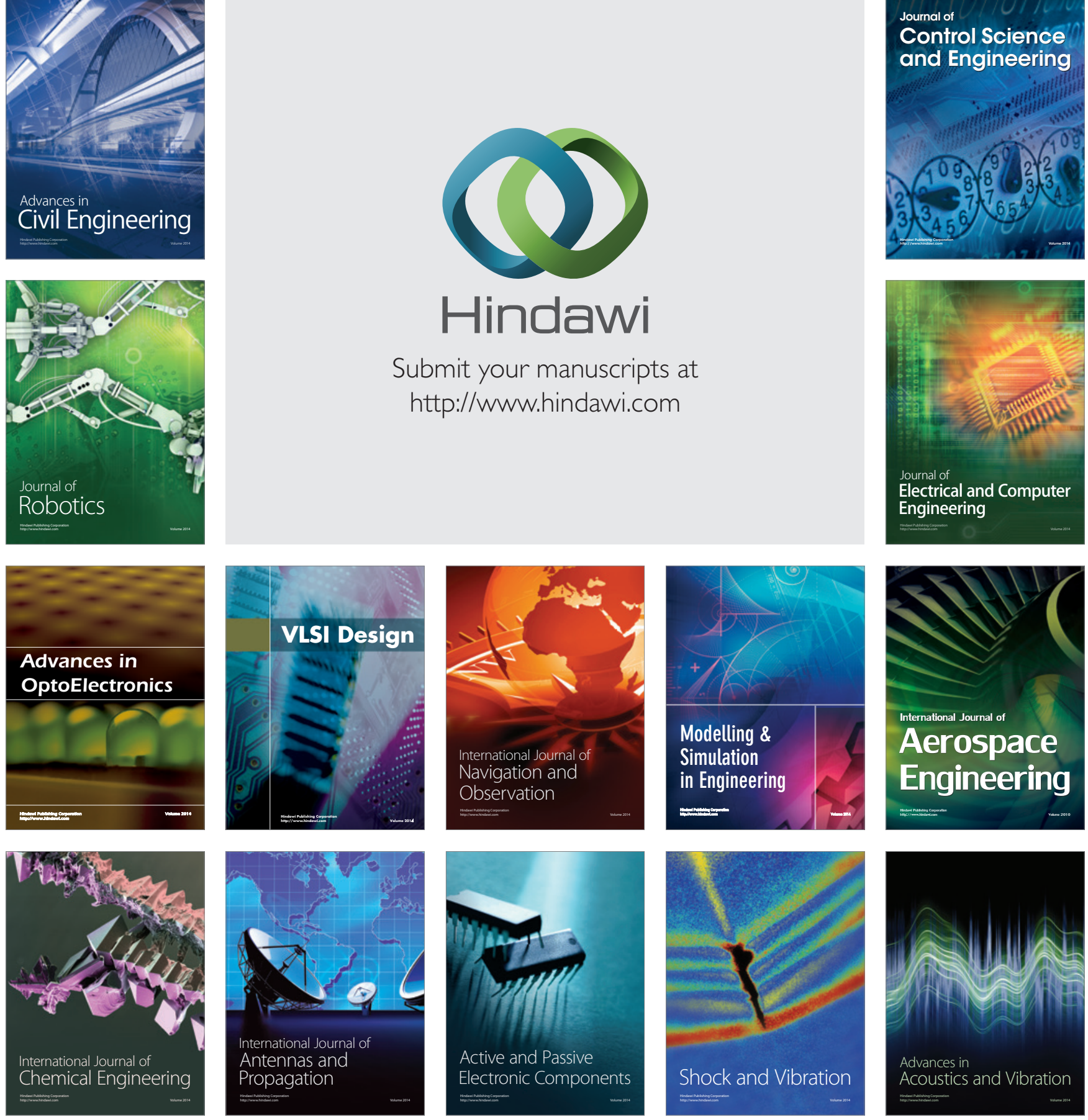